\title{
Anti-Racism Strategies in Pediatric Psychology: Using STYLE Can Help Children Overcome Adverse Experiences With Police
}

\author{
Rebecca L. Fix ${ }^{1}$ (I) Elizabeth Getzoff Testa ${ }^{2} \cdot$ Idia B. Thurston $^{3} \cdot$ Wendy N. Gray $^{4} \cdot$ Melvin T. Russell $^{5}$
}

Accepted: 30 June 2021 / Published online: 24 July 2021

() The Author(s), under exclusive licence to Springer Science+Business Media, LLC, part of Springer Nature 2021

\begin{abstract}
Black children are exposed to police violence at alarming rates. Such stress impacts development and treatment of physical health problems. In the current discourse, we introduce STYLE (Self-examination, Talk about community-police relations and racism, Yield space and time to anti-racism work, Learn about how structural racism impacts child health, Evaluate policies and practices through an anti-racism lens). STYLE offers a framework through which professionals in pediatric psychology can engage in anti-racist work across contexts from clinical care to academic and advocacy settings. Pediatric psychologists have a responsibility to be on the frontline as interventionists, educators, researchers, organizers, and advocates for racial justice through anti-racism practices. The current paper introduces STYLE in clinical care, community service, training/supervision, and academic and advocacy contexts. Case examples are provided. Professionals in pediatric psychology must first focus on changing their STYLE to promote individual and infrastructural change consistent with anti-racism work.
\end{abstract}

Keywords Anti-racism $\cdot$ Structural racism $\cdot$ Clinical $\cdot$ Training $\cdot$ Professional development

In the United States, there have been protests tied to police use of anti-Black violence which has resulted in an average of 200 deaths of Black people annually (Mapping Police Violence, 2019; Post, 2018). In 2020, nationwide protests against the role of systemic racism in the deaths of several Black-identified community members, including Ahmaud Arbery, Breonna Taylor, Daniel Prude, Elijah McCain, George Floyd, Rayshard Brooks, Tony McDade, and too many others (see Proctor, 2020), raised public awareness of these issues across the U.S. In response to this current context and public social justice response, families nationwide receiving pediatric psychology services increasingly noted their distrust of the police during therapy sessions. Given this context, we provide the following examples

Rebecca L. Fix

rebecca.fix@jhu.edu

1 Bloomberg School of Public Health, Johns Hopkins University, 415 N. Washington Street, Baltimore, MD 21231, USA

2 Mt. Washington Pediatric Hospital, Baltimore, USA

3 Texas A\&M University, College Station, USA

4 Children's Hospital of Orange County, Orange, USA

5 Baltimore City Police Department, Baltimore, USA as a basis for why pediatric psychologists need to be aware of and informed on how issues of anti-Black violence and policing impact the lives of children and families they serve.

In the U.S., $38.7 \%$ of the adult population, and $48.1 \%$ of the population under age 18, identify as people of color and/or Hispanic/Latinx (U.S. Census Bureau, 2019). It has been projected that over half the population in the U.S. will be Black, Indigenous, or other people of color (BIPOC) ${ }^{1}$ or Latinx by 2044 , and by 2060 , approximately $20 \%$ of the population will be identified as first generation, (i.e., being born outside the U.S. but residing permanently in the U.S.) (Colby \& Ortman, 2015). These shifts in U.S. demography have undoubtedly placed greater accountability on pediatric psychologists to engage in culturally responsive care, particularly considering the need for psychologists to upend racism (Buchanan et al., 2021) expand their knowledge base and improve practices and advocacy efforts for working with children from BIPOC-identified communities who are repeatedly exposed to systemic violence via communitypolice relations (Mulchan et al., 2021; Vasquez et al., 2006).

\footnotetext{
${ }_{1}$ We are using the BIPOC acronym to center Black and Indigenous people first because of the specific history of marginalization from enslavement and colonization and genocide that continues today, especially in the context of policing.
} 
In caring for children, pediatric psychologists are naturally exposed to a breadth of adverse childhood experiences (ACEs, e.g., child maltreatment, death of a caregiver, witnessing community violence) beyond health problems. For many children, their medical condition can also impact their well-being similarly to an ACE. Consistent with the biopsychosocial model (Engel, 1980), which focuses on the ways that biological, psychological, and social factors interact to impact the health of a child, ACEs impacts multiple levels of child well-being and health (Williams, 2018). However, there are many ACEs that are underexplored by pediatric psychologists including systemic violent interactions between BIPOC and Latinx community members and law enforcement officers (LEOs) in the United States (Dukes \& Kahn, 2017).

Pediatric psychology represents a unique opportunity to engage in anti-racist behavior across a range of contexts, namely within clinical practice, research, training, and advocacy settings. Pediatric psychologists are being called upon to increase knowledge, frequency, and agency in culturally responsive strategies to assess the impact of community-police relations on child and family health. Structural racism directly impacts individual and population health in part through mass incarceration and police violence. Structural racism, racial trauma, discrimination, and racial health inequities particularly within BIPOC-identified communities, cause long-lasting emotional and biological responses among children and their caregivers, including despair and increased stress reactivity (Bailey et al., 2017; Link \& Phelan, 1995).

Moreover, children from BIPOC-identified communities report higher rates of chronic illnesses like asthma, diabetes, and obesity relative to white-identified ${ }^{2}$ children (Benfer, 2017; Berry et al., 2010; Hughes et al., 2017; McDaniel et al., 2006; Nardone et al., 2018; Simons et al., 2018).These children are often seen in primary care and specialty clinics that are staffed by pediatric psychologists, providing opportunities for assessment and intervention. Pediatric psychologists often use the biopsychosocial model as a foundation for case conceptualization and the basis of treatment to improve health outcomes for children diagnosed with a chronic illness (Engel, 1980). As such, pediatric psychologists and pediatric psychology trainees need to be familiar with and understand how the 'social' aspect of the biopsychosocial model influences child health via their direct and indirect interactions with LEOs.

The present discourse focuses on elucidating the systemic problem of harmful policing practices in BIPOC

\footnotetext{
2 We are intentionally using different letter case for different racial groups. We capitalize Black to emphasize and increase awareness of the marginalization of Black racial identity. We use lower case for white in recognition that capitalization of the word "white" could be a form of white supremacy (for more information, see https://www. cjr.org/analysis/capital-b-black-styleguide.php).
}

communities, how these practices negatively impact the children with whom we work, and offers a place to start developing strategies for addressing such violent and traumatic interactions. To accomplish this, we aim to (1) use case examples to describe how children and families served within the context of pediatric psychology are impacted by negative LEO interactions, (2) broaden the discussion around negative LEO interactions with a focus on pediatric psychology, and (3) offer a framework (i.e., STYLE) and concrete strategies to intervene in pediatric care settings in response to unique systemic challenges faced by children from BIPOC communities in the U.S who are systematically exposed to negative LEO interactions.

\section{Case Examples}

\section{Lessons From Direct Patient Care}

The complexities of children's chronic illness and the psychological impact of interactions with LEOs in the following case examples are commonly seen by pediatric psychologists. The cases presented are real clinical interactions deidentified for privacy. These cases are likely representative of the experiences of many children who live in neighborhoods relegated for BIPOC- and low-income communities, and experience high levels of systemic racism and warranted mistrust in police (Desmond et al., 2016; Schuck, 2013; Tyler et al., 2015). These examples illustrate the need for pediatric psychologists to receive additional education on how the adverse events of negative LEO interactions impact the mental and physical health of their patients.

\section{Pediatric Psychology in Individual and Family Care Settings}

\section{Individual Case Examples}

"Kiara" is a 13-year-old Black-identified adolescent girl living in an urban city in the mid-Atlantic region of the U.S. who was diagnosed with asthma, environmental allergies, juvenile arthritis, and attention-deficit hyperactivity disorder. In one of her individual sessions, she discussed a recent negative interaction she had with a LEO. She described walking down the street with a friend and seeing a police car drive past her, slow down, and then turn around. Then the police officers exited their vehicle and asked her to stop. Kiara described feeling fearful and having thoughts that she could be killed. They handcuffed her on the street and questioned her alone for over an hour before allowing her to call her mother to take her home. This method of racial and ethnic profiling is not new, but for a Black-identified adolescent with a complicated health profile, this event 
contributed significantly to increased physical and emotional distress. Kiara had done nothing illegal and was not given a reason for why she was detained. She was dehumanized by LEOs and given no rationale. She left the experience feeling embarrassed, confused, and scared. In addition, she was physically sore from the handcuffs that were placed on her wrists, which complicated her juvenile arthritis.

Another example that demonstrates intergenerational racial trauma involves "Destiny" a Black adolescent girl age 15 with Type 1 Diabetes. In one noteworthy session, Destiny discussed a coping mechanism she had put in place after learning about several highly publicized cases of police brutality and discussing racism with her family. She described dedicating time to learn about farming and which crops she could grow to help her control her blood sugar for, "when [she] is not welcome in society anymore." This case exemplifies how learning about police brutality, experiencing intergenerational race-based trauma, and increased awareness of tensions between LEOs and Black community members, can significantly shape a child's world views in response to medical problems.

These individual case examples elucidate the feelings youth may have that shape their behavior not only at the community level but also within medical institutional settings. Kiara had a direct experience with a police officer during which she was afraid for her life. Due to vicarious trauma from publicized policing incidents, Destiny believed that structural racism in policing meant she would eventually be unable to continue her medical care. Destiny believed she needed to accept the onus of her own care and was making plans accordingly. Such a response to anticipated trauma could be reframed as a resilient response-it is proactive, planful, and could lead to healthier choices. Yet traumatic encounters between youth and LEOs are uniquely impacted by racism. While both Kiara and Destiny were open to discussing these thoughts, many Black-identified youth may not volunteer their worries about these topics without a certain level of engagement and trust from their provider. However, these types of thoughts reflect thinking and perceptions that can dramatically impact treatment seeking behavior and adherence among Black-identified children and adolescents. Notably, even though both girls disclosed these concerns to their clinicians, one of them-Destiny-did not follow up with her provider several months later. Such cases demonstrate the need for pediatric psychologists to broach topics of police violence with patients and develop skills to handle such situations when they arise.

\section{Family Case Example}

"DeAndre," a 10-year-old boy diagnosed with severe obesity, obstructive sleep apnea, asthma, and a mood disorder and his family were impacted by systemic anti-Black racism. Their family was initially referred because DeAndre had threatened his mother's life, pulling a knife on her and threatening to kill her as she slept. During a family therapy session, DeAndre's mother stated she would never call the police despite her son's concerning behavior, because she believed that calling the police would increase the odds of death for someone in her home beyond her son's gestures.

The legacy of systemic racism against Black-identified families drives a deep distrust of police who are tasked to serve and protect the communities they serve. This mistrust has an impact on the care provided by mental health practitioners and may lead to reduced treatment seeking behavior by families. There are very recent examples of mental health disturbance preceding police violence. For example, in September 2020 in Salt Lake City, a white adolescent boy diagnosed with Autism was shot several times by a LEO after his mother called police for his behavioral disturbance (NPR, 2020). Apprehension from the systematic violence toward BIPOC communities is further exacerbated by mental illness and, thus, addressing such violence is critical for psychologists.

\section{Community Case Example}

Experiences of a school-aged Black-identified girlTonya-being seen in a Stage III weight management clinic illustrates systems level impact of policing. During an individual therapy session, Tonya expressed that she is not allowed to play outside. She explained that since the protests following the killing of Freddie Gray, there has been an increased frequency of police officers patrolling in her neighborhood. She described how her parents feared for their own and her interactions with the patrolling LEOs, and taught her not to speak or interact with them. More specifically, she said that her parents are afraid that the LEO will become violent towards them and possibly her. Tonya's parents remarked that it was preferable to have 'drug dealers' in their neighborhood because they knew the people who sold drugs would leave them alone, whereas they were uncertain how police would engage with them.

Current events involving police officers shooting and killing Black citizens also appear to disproportionately interrupt care for children in BIPOC communities. Following the recent death of George Floyd, there were a number of protests-many of which took place in cities where there were a high number of BIPOC community members. Due to the potential threat of violence, many hospitals shut down clinics in those communities. Thus, youth (who were mostly BIPOC or Latinx) in the surrounding community did not get needed medical care whereas youth in more affluent areas did not experience any disruption in their care. Such experiences further widen the health disparity gap. 


\section{Pediatric Psychology in Community Settings}

\section{Grassroots Community Case Example}

In an effort to restructure community-police relations in Baltimore City, MD a grassroots program was developed in collaboration with the Baltimore City Police Department Community Collaboration Division. The goal of the program was to design a comprehensive community program called MENTOR-Mindfulness Engaging ' $N$ ' Open-minded Relationships. The program was co-sponsored by the second author's institution and the Baltimore City Police Department. The program was offered 3 hours a month to five children (ages 8-12 years) and their caregivers to improve well-being at home and in the community. Classes were co-facilitated by a white pediatric psychologist and a Black LEO from the Baltimore City Police Department Community Collaboration Division. The two primary goals of the program were to: (1) promote healthy positive interactions between LEOs and children and families and (2) increase child and family comfort with police officers. We worked with three LEOs from the Community Collaboration Division (one Black-identified male sergeant and two Black-identified female officers) - one of these police officers was the woman who co-facilitated MENTOR.

Building new interdisciplinary collaborative relationships can be challenging. During the first meeting with the program organizers, the sergeant questioned the white pediatric psychologist repeatedly about why race relations mattered to her. He inquired about her ethnic and religious background as well as the derivation of the psychologist's last name. It was unclear why these personal questions were asked but it was noted that once the institution's Community Advocacy Manager who is Black-identified joined the meeting, the sergeant became more at ease with the collaboration and did not ask further questions nor did he insist on getting answers to the questions he had posed to the psychologist. Thus, it was challenging for both the sergeant and the pediatric psychologist to find common ground and develop trust in the beginning of their working relationship.

After the second session of MENTOR, Freddy Gray was killed in police custody, requiring reorganization of the program. For example, it was planned that the LEOs would dress in plain clothes throughout the program to ease rapport building and promote comfortability between the LEOs and families. However, after the death of Freddy Gray, officers were required by the police department to wear a full uniform while on duty, including bulletproof vests. Upon the LEO attending group in full uniform, one child member remarked, "[I] did not know that she was a
LEO and thought she was a person." It became clear that the association between police uniforms with danger and fear was robust for participating community membersparticularly the children. Additionally, there appeared to be a dehumanizing effect of the LEO when she wore her uniform that was not there the previous week when she was dressed in plain clothes. Interestingly, the LEO's rapport and relationship with the children and families in MENTOR may have deemphasized the stimulus value of police identity (and beliefs participants had about police as distrustful and violent toward Black communities). Ultimately, participating MENTOR community members viewed the LEOs as more relatable as noted in feedback from a post-program satisfaction questionnaire (intended for use in applied settings and developed to inform future iterations of MENTOR) administered at the end of the group, with participant responses suggesting a comfort level with LEOs that ranged from neutral to pleasant.

\section{Introducing STYLE}

The case examples provided in the current text demonstrate the complexities of providing care in pediatric psychology settings to BIPOC and Latinx children, adolescents, and their families who have had negative experiences with police. Through the authors' clinical experiences, it has emerged that there is a necessity in developing strategies for pediatric psychologists to expand their skillset and engage in practices aligned with anti-racist ideals. In response to the need for pediatric psychologists to address issues of structural racism that are often overlooked in medical settings, we rely on the STYLE framework (Fix et al., 2021). The STYLE framework was developed based on ecological systems theory, which centers around the notion that our individual behavior and health is impacted by interconnected systems, including the educational and justice systems (Reskin, 2012). Experts recognize the need to target multiple interconnected systems to address structural racism (Williams and Purdie-Vaughns, 2016), and the need to focus on oppression of BIPOC and Latinx people and privilege of white people (Nixon, 2019). Further, there has been an identified need for development of such skills in the field of pediatric psychology (Mulchan et al., 2021).

Self-examination and critical reflection to improve awareness and understand personal experiences of oppression, privilege, biases, and reasons for inaction; Talk directly about police-community relations and structural racism in your work;

Yield time and space to anti-racism work; 
Learn about structural racism, the justice system, and how racism impacts BIPOC youth, their families, and their communities;

Evaluate policies and practices through an anti-racism lens.

Through the incorporation of STYLE principles (see Table 1), pediatric psychologists can practice anti-racist strategies and join the fight to dismantle structural racism. In the sections that follow we often situate STYLE within the context of clinical work. We then briefly address strategies for engaging with STYLE in academic settings and becoming involved in advocacy efforts to promote equitable and anti-racist practices at a policy level.

\section{STYLE in Pediatric Psychology Clinical Work}

Incorporating the STYLE principles in clinical work is an act of anti-racism as pediatric psychologists serve as a link between families and communities. Through increased knowledge and awareness, pediatric psychologists can inform and engage in clinical, training, and mentoring practices that address harmful LEO encounters among children from BIPOC-identified communities, particularly Blackidentified children who are systematically impacted. Below we identify several key strategies for: (1) self-examination (S) about your own experiences and biases; (2) talk (T) about racism and how the justice system disproportionately impacts children from BIPOC-identified communities; (3) yielding (Y) time and space, (4) learning (L) about racism in policing and how it impacts care in individual and family health care, community, and academic settings; and (5) evaluate (E) policies and practices that directly and indirectly influence pediatric psychology through an anti-racism lens.

\section{Self-Examination to Increase Awareness (STYLE)}

Pediatric psychologists are encouraged to improve their selfawareness about how racism manifests in their practice and seek out continuous educational opportunities (Mulchan et al., 2021). Promoting a trauma-informed approach and trauma-informed care has been a major policy initiative within the Society of Pediatric Psychology and the American Academy of Pediatrics since the landmark study linking adverse childhood events (e.g., childhood abuse, violence exposure) to many leading causes of death in adulthood (Felitti et al., 1998). It is, thus, a primary responsibility of professionals working with pediatric populations to utilize trauma-informed care and be intentional in screening for traumatic experiences with LEOs, systemic and institutional racism, and racial trauma (DeVault et al., 2018). Given that racism is a fundamental cause of disease and, thus, a driver of racial health inequities (Boyd et al., 2020), pediatric psychologists should assess for and label systemic racism in reports and develop and implement interventions that intentionally integrate these factors (Link \& Phelan, 1995). This necessary change in the way we practice pediatric psychology can only occur via a process of deep learning and putting that learning into practice. We highlight specific areas for the deep learning to occur in Table 1.

\section{Self-Awareness}

We strongly encourage pediatric psychologists to engage in identity exploration and acknowledgement (for example by using the ADDRESSING framework (Hays, 2009) to explore your own identities and understand your own privileges and oppressions). Because this paper centers race and ethnicity (and oftentimes nationality) children from BIPOCidentified communities represent salient sources from whom we can learn. Note that learning does not entail asking BIPOC children to educate someone about racism - the onus to educate yourself should not be placed on children we serve. Learning about whiteness and racial and ethnic identity - and how these identities impact power dynamics in professional spaces-is important for effectively working with white and BIPOC-identified children and their families (Okun, 2014; Seller et al., 1998; Sue, 2010). BIPOC patients and their families are often familiar with their minoritized racial and ethnic status and, thus, are immediate sources of knowledge on their own racialized experiences. Sellers and colleagues demonstrated that a higher level of racial identity protects against the negative impacts of racism (Sellers et al., 1998, 2003). But even the highest levels of racial identity cannot protect against physical harm, and particularly when the harm is inflicted by individuals with power. Accordingly, the onus of protecting citizens needs to be on both breaking down institutional racism and on professionals exploring their own identities and ways they contribute to or maintain systems of structural racism. As a first step, pediatric psychologists need to turn their professional energy and time to anti-racism work, following queues from the BIPOC community. 


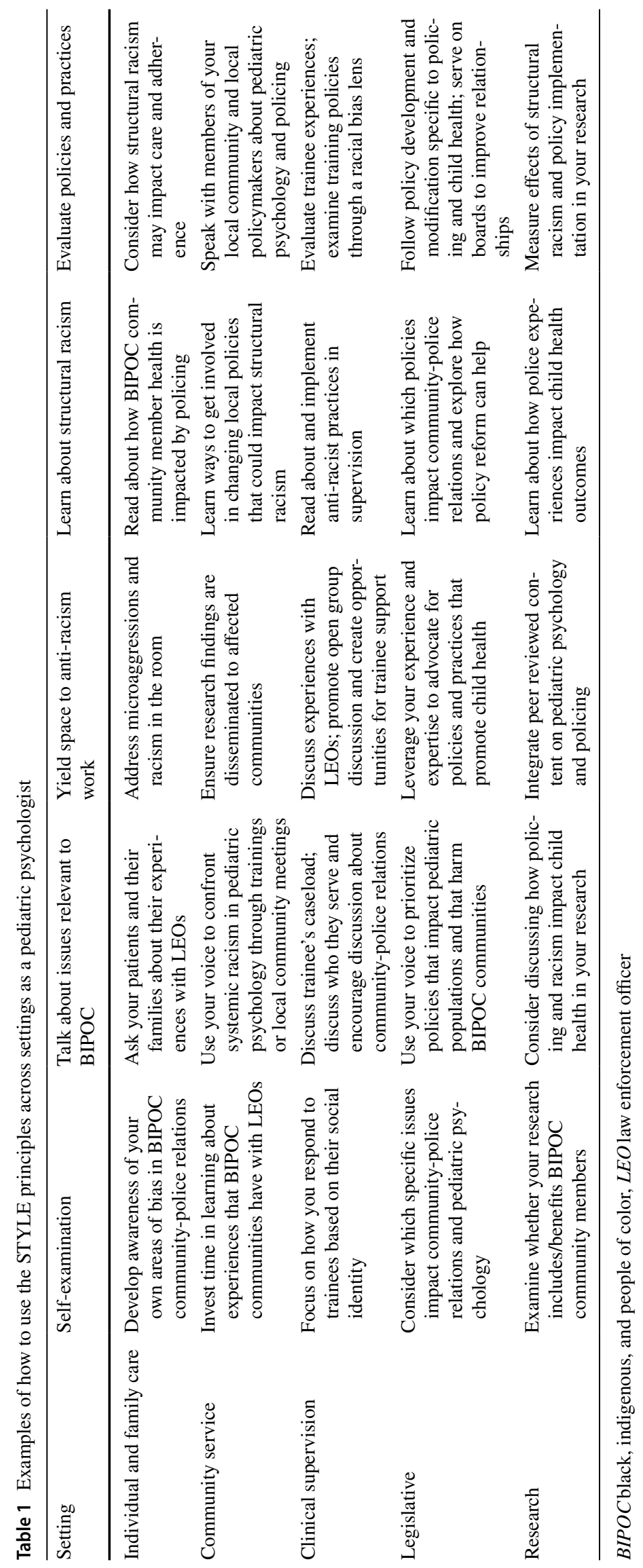




\section{Talk About Individual and Structural Racism Across Pediatric Psychology Contexts (STYLE)}

\section{Terminology}

To talk effectively about racism, it is important to use accurate language. Expand your knowledge and do a self-assessment of your use of Systems-Centered Language (O'Reilly, 2020) in clinical reports, research manuscripts, and verbal communication with interdisciplinary teams. Systems-Centered Language is similar to person first language, where the person is put before the disease (e.g., child with obesity rather than obese child). Systems-Centered Language is a "linguistic call to action that seeks to end the dehumanization of people that occurs while discussing how they are experiencing oppression" (O'Reilly, 2020). Examples might include reporting every patient's identified race and ethnicity (e.g., "Rachel is a Black-identified girl," "John is a whiteidentified boy") and describing population experiences with terms that highlight the influence of the system (e.g., "Considering that the COVID-19 pandemic is hitting our most constrained (rather than vulnerable) populations the hardest, Andrea would benefit from culturally responsive approaches to therapy"). This paper joins other work pushing for the use of Systems-Centered Language in academic writing (e.g., Buchanan et al., 2021; Valrie et al., 2020) in clinical reports and charting in patients' medical records.

\section{Racial Inequity Awareness}

Pediatric psychologists should independently read about and seek out trainings on becoming anti-racist, and to provide appropriate care guided by an intersectional approach-one that considers all ADDRESSING categories. To help understand the three levels of racism, readers are encouraged to study Camara Jones' The Gardener's Tale (Jones, 2000). To better understand harm and oppression that result from multiple intersecting systems mired by racism, readers are encouraged to learn Marilyn Frye's birdcage metaphor (Frye, 1983). Lessons learned should be incorporated into existing pedagogy, training, and supervision within the field of pediatric psychology. Pediatric psychologists must recognize and understand how community-police experiences differ within BIPOC communities and between white and BIPOC communities. Increased awareness of the violence and racial trauma directly and indirectly inflicted upon Black-identified children and families during encounters with LEOs is vital. Such awareness can better prepare practitioners, researchers, and educators of pediatric psychology trainees in providing informed care to those they serve.

\section{Yield Time and Space to Anti-Racism Work (STYLLE)}

\section{Providing Clinical Care to Children with Law Enforcement Officer Exposure}

Mistrust and fear in LEOs following exposure to LEO violence may negatively impact youth from BIPOC-identified communities (Tyler et al., 2015). Some individuals may avoid seeking assistance from LEOs, whereas others might feel helpless in their ability to protect themselves or the ones they love from fatal or non-fatal injury by LEOs. The constellation of these problems resulting from LEO violence produce a substantial challenge for mental healthcare providers. Specific strategies for working with children exposed to violence have been outlined by a number of scholars, though to our knowledge, no known interventions have focused on strategies for delivering pediatric psychology treatments for children from BIPOC-identified communities who have been exposed to LEO violence.

\section{Direct Work With LEOs}

Pediatric psychologists should develop and conduct trainings and make single-page fact sheets and create other resources to improve LEO knowledge in ways that reduce systemic violence during community-police relations. Programs to educate LEOs should highlight child and adolescent development, differences between adolescent and adult neurophysiology, normative risk taking during this developmental phase, how youth with common mental health problems present (e.g., youth may have PTSD and look away from a LEO during interactions out of fear-not because they did something wrong) and the importance of limiting further exposure to trauma and violence in children and adolescents (Fix et al., 2021; Thurau, 2015). Pediatric psychologists can play a role in informing LEOs about the need to increase positive contact with youth from BIPOC-identified communities outside of justice-based interactions, as well as seek out opportunities for self and LEO exposure to counter-stereotypical images and stories of BIPOC and Latinx individuals in order to reduce racial biases that impact interactions with members of BIPOC communities (Lai et al., 2014).

\section{Commitment to Equity, Advocacy, and Justice}

Pediatric psychologists should communicate and display their social justice values so that patients and families are aware of where they stand. In a similar vein to how we comment on our therapeutic orientation, we should not assume that patients "know" we are advocating for them, without telling/showing this to them. Strategies for demonstrating 
your commitment to anti-racism could be as simple as having books with Black protagonists and Black dolls to having Black Lives Matter signs or artwork created by and/or depicting BIPOC community members in one's practice. It can also be helpful to talk directly with patients about your commitment to anti-racist practice. Given that racism is systemic and embedded in institutional structures, pediatric psychologists should be advocating and working to change policies across settings (from hospitals to academic centers to universities) to dismantle and change systemic practices that maintain and enable racist practices and, thus, drive health inequities.

\section{Learn How Structural Racism in the Justice System Impacts Pediatric Populations (STYLE)}

Education is important to ensure a baseline level of understanding of the problem of structural racism in policing. In the U.S., police violence toward civilians is systematically experienced and witnessed at disproportionately elevated rates by BIPOC community members (Brunson \& Miller, 2006; Cauffman et al., 2007; Hyland et al., 2015). In neighborhoods with fewer economic resources that are relegated for BIPOC, strategies utilized by LEOs like increased surveillance, contact, and force are harmful to these community members, including children (Brunson \& Miller, 2006; Fagan \& Davies, 2000). BIPOC and Latinx communities are systematically exposed to greater rates of interactions with LEOs compared with white-identified individuals. Blackand Latinx-identified community members are subjected to 3.5 and 2.1 times more threat or force by LEOs, respectively, compared with white-identified individuals (Brunson \& Miller, 2006; Fagan \& Davies, 2000; Hyland et al., 2015). Due to the higher rates of arrest and incarceration for BIPOC community members, BIPOC-identified children are systematically exposed to higher rates of witnessed and experienced arrests (Geller et al., 2009), resulting in a number of mental health sequelae-especially symptoms of anxiety, depression, and PTSD (Bryant-Davis et al., 2017).

Rates of violence by LEOs in the United States are truly alarming - in 2015 alone, approximately 1,000 people were killed by LEOs (Post, 2018), and over 1,100 people were killed by LEOs in 2018 (Mapping Police Violence, 2019), with BIPOC and Latinx community members more likely to be killed by LEOs than white-identified individuals (Gabrielson et al., 2014; Scott et al., 2017), even in LEOon-LEO shootings (Charbonneau et al., 2017). Children from BIPOC-identified communities are also overrepresented among child arrests, convictions, and confinement
(Hockenberry \& Puzzanchera, 2015). For instance, Blackidentified children represent $7 \%$ of the U.S. population (U.S. Census Bureau, 2019), yet over 33\% of children who are arrested are Black-identified (Loeber et al., 2013).

In response to harmful and disproportionate interactions with LEOs, perceptions of LEOs are the most negative among Black-identified children (Nadal et al., 2017). Research on LEO violence exposure among Black-identified children suggests such exposure not only negatively impacts their physical and mental health alongside their social development but can also result in changes to their belief systems about safety (Staggers-Hakim, 2016). Ultimately, these changes could extend to other relationships and systems outside of the community-policing relationship. Whether direct (e.g., witnessing, experiencing) or indirect (e.g., learning about, seeing incidents via media), child exposure to racial trauma and violence by LEOs could impact their clinical care, and, thus, failure to assess and offer therapeutic support for this type of trauma could be considered a major gap in care.

\section{Seek out Continued Education}

How and where can you learn more about ways in which structural racism can impact patients in pediatric psychology? For those who identify their race as white, the answer is not from a colleague, peer, or patient who is a member of a BIPOC community (DiAngelo, 2018). Just because nonwhite colleagues, peers, and patients are salient sources from whom we can learn, there are ample resources to self-educate or learn from other sources without placing increased burden on BIPOC individuals. There is an extensive body of literature on racism, including how to conceptualize the three levels of racism (Jones, 2000), for white professionals - how to understand one's own whiteness (DiAngelo, 2018), and how to conceptualize anti-racism (Kendi, 2019). Those interested in better understanding bias and strategies for mitigating its harmful effects are encouraged to read further on the topic (see Eberhardt, 2020). Additionally, there are multiple online talks by experts on racism and bias and in-person workshops that you could promote at your workplace. For professionals in pediatric psychology who are in leadership positions within professional organizations, seeking out speakers who will address this topic could allow more widespread dissemination of knowledge relevant to addressing how structural racism-namely that in community-police relationships-impacts the health and medical care of their patients and individuals and families with whom they do research. 


\section{Evaluate Policies and Practices (STYLE)}

The evaluation aspect of the STYLE principle can be applied across contexts but is especially apparent and relevant in academic and advocacy settings. Incorporating the STYLE principles in academic settings offers a path forward to promote anti-racism through changes in policies and practices. For example, BIPOC and Latinx faculty and students are often tasked with a greater burden of addressing systemic racism, serving/leading diversity committees, mentoring students, and teaching diversity courses (Griffin \& Reddick, 2011). People in leadership positions should ensure (1) that members of the BIPOC and Latinx communities are not overwhelmed by this work, (2) that this work is not hindering faculty member's productivity required to get tenure, and (3) that faculty are compensated for their time in doing anti-racism work. Compensation for one's time is essential in this work, given that members of BIPOC and Latinx communities are more often called upon or asked by students to take on these typically unpaid, under recognized, and less highly-regarded roles (Griffin \& Reddick, 2011).

Research in pediatric psychology should target how interpersonal and structural racism in the justice system and other interconnected systems impact children's health and health outcomes. Recognizing that systems are interconnected-for example the medical system and justice system-could meaningfully improve research aimed at understanding pediatric health (Reskin, 2012). Briefly, researchers must learn: (1) existing prevention and intervention techniques targeting racism and health, (2) the effectiveness of existing prevention and intervention techniques, (3) required measures and methods to prevent negative health outcomes following police interactions, and (4) how pediatric psychologists might better examine racism in policing and associated negative health outcomes.

Evaluation work is especially applicable within social justice and advocacy settings. Pediatric psychologists have a unique skillset and exposure to the medical system, putting them in a position to affect meaningful change. Pediatric psychologists are encouraged to be self-, other-, and system-focused when working with patients or when conducting research or engaging in advocacy work. Finally, openly advocate for system-based change.

\section{Conclusion}

Where do we go from here? In the United States, mistrust between members of BIPOC and Latinx communitiesparticularly members of the Black community-and police is deeply enmeshed in a history of racism and oppression.
One particularly problematic aspect of many existing interventions and programs aiming to mend community-police relations is that they place the onus of change on children instead of providers or, more importantly, LEOs. Providers must be informed and ready to talk about race, institutional racism within police departments, and racial trauma. Through the STYLE principle, professionals who work in pediatric psychology can build upon their unique skillset and expertise. The primary barriers to anti-racism work for pediatric psychologists include: (1) a lack of prioritization of the problem of racism, (2) decreased access to and awareness of resources to address racism, (3) limited clarity about the pivotal role that pediatric psychologists can play in working with children from BIPOC communities who are survivors of systemic LEO trauma, and (4) a paucity of data and knowledge about how to help improve community-LEO relationships as a pediatric psychologist.

In the above discourse, we described how children who live in BIPOC and Latinx communities are systematically exposed to elevated levels of police violence as exemplified by case examples. We also provided a frameworkSTYLE- and associated strategies for building skills to be an effective clinician, educator, researcher, and advocate in pediatric psychology to children from BIPOC-identified communities in the U.S., and particularly those who have a history of mistrust or harm during interactions with LEOs.

Altogether, recognition of the dynamic between LEO violence and child development is crucial to our ability to effectively respond to and serve children from BIPOC-identified communities. A meta-analysis of the relationship between discrimination and mental health indicated that discriminatory experiences trigger the stress response (Pascoe \& Smart Richman, 2009), such that experiencing discrimination can trigger a harmful physiological and psychological response. A second meta-analysis indicated perceived discrimination contributed to substantially decreased psychological wellbeing (e.g., depression, anxiety, low self-esteem), an effect that was greater among children relative to adults (Schmitt et al., 2014). In response to research supporting racial and ethnic stereotyping as the predominant explanation for LEO violence (Jones, 2017), LEO trainings have been developed and implemented to reduce such violence (Smith, 2015). However, most such trainings are not developmentallyinformed or comprehensive in scope (e.g., do not incorporate intersectionality).

There remains a paucity of research on attitudes and beliefs held by LEOs toward children from BIPOC-identified communities, especially children who become enmeshed in the justice system. Data from this scant body of literature indicate that working with children in non-legal settings may improve LEO's general attitudes toward children from BIPOC-identified communities (Goodrich et al., 2014). Negative attitudes held by LEOs toward children from 
BIPOC-identified communities are not set in stone; trainings specific to LEOs that address unique developmental and trauma-specific responses of adolescents to LEOs indicate that perceptions about adolescents can become more positive over time and an appreciation for adolescence as a period of stress can increase through training (Schwartz et al., 2017). The limited data on LEO attitudes suggest that LEO-child interactions might be improved through education and greater exposure to children in non-law enforcement situations.

Pediatric psychologists are well positioned to work within an interdisciplinary team; in fact, it is a key aspect of training for pediatric psychologists. This skillset can easily be transformed into working with community organizations involving collaborations with LEOs, organizations that serve LEOs, and communities whose lives are systematically impacted by LEO interactions. As pediatric psychologists, our mission is to "actively promote the health and psychological well-being of all children, youth and families." Systemic racism, racial trauma, and racial discrimination are critical components of the biopsychosocial model that influence the health of children from BIPOC-identified communities. Thus, as pediatric psychologists, we have a duty to assess, understand, and address these issues. Further, given the systemic nature of racism, to do such work will require us to step outside our offices to advocate via engagement and policy reform.

Recent events fostered development of task forces within professional organizations that allow interested professionals to lend their voices and knowledge to help their patients and students outside of therapy sessions and the classroom, respectively. APA offers relevant training opportunities to psychologists interested in building relationships within the community. There are two predominant task forces developed by the APA tackling these issues. These include the Presidential Task Force to Reduce Police Violence Against African Americans and the Task Force on Strategies to Eradicate Racism, Discrimination, and Hate (Public Interest Directorate). The anti-racist taskforce created by the Society of Pediatric Psychology also aims to offer training and advocacy opportunities for professionals in pediatric psychology. In response to recent killings of Black citizens by LEOs, the Society of Pediatric Psychology encouraged professionals in the field to voice their experiences in writing narratives on racial trauma and justice. This work must be supported lest we lose momentum and revert to the status quo.

Pediatric psychologists who improve their STYLE can improve the well-being of the children and families they serve. Professionals in pediatric psychology have the capacity to help repair and heal the physiological, psychological, and mental health of children from BIPOC-identified communities. Our expertise can demonstrably improve the physiological and psychological well-being of members of
BIPOC and Latinx communities and LEOs. Pediatric psychology has the power to influence development of competent police leadership focused not only on safety for all citizens, but to also respond to needs of children and families from BIPOC-identified communities who experience harm during interactions with LEOs and to promote healthier community-police relationships through anti-racism work. We strongly encourage you to adopt STYLE: self-examination, talking about racism and how it impacts the children and families we serve, yielding time and space to BIPOC and Latinx community members, learning about racism in policing, and evaluating policies and practices that might impact our field and those children and families we aim to serve.

\section{Compliance with Ethical Standards}

Conflict of interest The authors have no potential conflicts of interest to declare.

Informed Consent Not Applicable.

\section{References}

Bailey, Z. D., Krieger, N., Agénor, M., Graves, J., Linos, N., \& Bassett, M. T. (2017). Structural racism and health inequities in the USA: Evidence and interventions. The Lancet, 389(10077), 1453-1463.

Benfer, E. A. (2017). Contaminated childhood: How the United States failed to prevent the chronic lead poisoning of low-income children and communities of color. Harvard Environmental Law Review, 41, 493.

Berry, J. G., Bloom, S., Foley, S., \& Palfrey, J. S. (2010). Health inequity in children and youth with chronic health conditions. Pediatrics, 126(Supplement 3), S111-S119.

Boyd, R. W., Lindo, E. G., Weeks, L. D., \& McLemore, M. R. (2020). On racism: A new standard for publishing on racial health inequities. Health Affairs Blog. https://doi.org/10.1377/hblog20200 630.939347

Brunson, R. K., \& Miller, J. (2006). Gender, race, and urban policing: The experience of African American youths. Gender \& Society, 20(4), 531-552.

Bryant-Davis, T., Adams, T., Alejandre, A., \& Gray, A. A. (2017). The trauma lens of police violence against racial and ethnic minorities. Journal of Social Issues, 73(4), 852-871.

Buchanan, N., Perez, M., Prinstein, M. J., \& Thurston, I. B. (2021). Upending racism in psychological science: Strategies to change how our science is conducted, reported, reviewed and disseminated. American Psychologist. https://doi.org/10.31234/osf.io/ $6 \mathrm{nk} 4 \mathrm{x}$

Cauffman, E., Piquero, A. R., Kimonis, E., Steinberg, L., Chassin, L., \& Fagan, J. (2007). Legal, individual, and environmental predictors of court disposition in a sample of serious adolescent offenders. Law and Human Behavior, 31(6), 519-535. https://doi.org/ 10.1007/s10979-006-9076-2

Charbonneau, A., Spencer, K., \& Glaser, J. (2017). Understanding racial disparities in police use of lethal force: Lessons from 
fatal police-on-police shootings. Journal of Social Issues, 73(4), 744-767.

Colby, S. L., \& Ortman, J. M. (2015). Projections of the size and composition of the US population: 2014 to 2060. US Census Bureau

Desmond, M., Papachristos, A. V., \& Kirk, D. S. (2016). Police violence and citizen crime reporting in the black community. American Sociological Review, 81(5), 857-876.

DeVault, A., Helfrick, V. A., Marsh, S. C., \& Snider, K. M. (2018). Environmental considerations for trauma-responsive juvenile and family courts: A review of the literature with recommendations for practice. Juvenile and Family Court Journal, 69(2), 5-20.

DiAngelo, R. (2018). White fragility: Why it's so hard for white people to talk about racism. Beacon Press.

Dukes, K. N., \& Kahn, K. B. (2017). What social science research says about police violence against racial and ethnic minorities: Understanding the antecedents and consequences-an introduction. Journal of Social Issues, 73(4), 690-700.

Eberhardt, J. L. (2020). Biased: Uncovering the hidden prejudice that shapes what we see, think, and do. Penguin Books.

Engel, G. L. (1980). The clinical application of the biopsychosocial model. American Journal of Psychiatry, 137(5), 535-544.

Fagan, J., \& Davies, G. (2000). Street stops and broken windows: Terry, race, and disorder in New York City. Fordham Urban Law Journal, $28,457$.

Felitti, V. J., Anda, R. F., Nordenberg, D., Williamson, D. F., Spitz, A. M., Edwards, V., \& Marks, J. S. (1998). Relationship of childhood abuse and household dysfunction to many of the leading causes of death in adults: The adverse childhood experiences (ACE) study. American Journal of Preventive Medicine, 14(4), 245-258.

Fix, R. L., Aaron, J., \& Greenberg, S. (2021). Experience is not enough: Self-identified training needs of police working with adolescents. Policing: A Journal of Policy and Practice. https:// doi.org/10.1093/police/paab039.

Frye, M. (1983). The politics of reality: Essays in feminist theory. Crossing Press.

Gabrielson, R., Jones, R. G., \& Sagara, E. (2014). Deadly force, in black and white. ProPublica.

Geller, A., Garfinkel, I., Cooper, C. E., \& Mincy, R. B. (2009). Parental incarceration and child well-being: Implications for urban families. Social Science Quarterly, 90(5), 1186-1202.

Griffin, K. A., \& Reddick, R. J. (2011). Surveillance and sacrifice: Gender differences in the mentoring patterns of black professors at predominantly White research universities. American Educational Research Journal, 48(5), 1032-1057.

Hays, P. A. (2009). Integrating evidence-based practice, cognitivebehavior therapy, and multicultural therapy: Ten steps for culturally competent practice. Professional Psychology Research and Practice, 40(4), 354.

Hockenberry, S., \& Puzzanchera, C. (2015). Juvenile court statistics 2013. National Children's Advocacy Center.

Hughes, H. K., Matsui, E. C., Tschudy, M. M., Pollack, C. E., \& Keet, C. A. (2017). Pediatric asthma health disparities: Race, hardship, housing, and asthma in a national survey. Academic Pediatrics, 17(2), 127-134.

Hyland, S., Langton, L., \& Davis, E. (2015). Police use of nonfatal force, 2002-2011. Washington: US Department of Justice Office of Justice Programs, Bureau of Justice Statistics.

Jones, C. P. (2000). Levels of racism: A theoretic framework and a gardener's tale. American Journal of Public Health, 90(8), 1212 .

Jones, J. M. (2017). Killing fields: Explaining police violence against persons of color. Journal of Social Issues, 73(4), 872-883.

Kendi, I. X. (2019). How to be an antiracist. London, United Kingdom: One World.

Lai, C. K., Marini, M., Lehr, S. A., Cerruti, C., Shin, J. E. L., JoyGaba, J. A., \& Koleva, S. P. (2014). Reducing implicit racial preferences: I. A comparative investigation of 17 interventions. Journal of Experimental Psychology General, 143(4), 1765.

Link, B. G., \& Phelan, J. (1995). Social conditions as fundamental causes of disease. Journal of Health and Social Behavior, 80-94.

Loeber, R., Farrington, D. P., \& Petechuk, D. (2013). Bulletin 1: From juvenile delinquency to young adult offending (study group on the transitions between juvenile delinquency and adult crime). US Department of Justice Office of Justice Programs

Mapping Police Violence. (2019). National police violence map. Retrieved from https://mappingpoliceviolence.org/

McDaniel, M., Paxson, C., \& Waldfogel, J. (2006). Racial disparities in childhood asthma in the United States: Evidence from the National Health Interview Survey, 1997 to 2003. Pediatrics, 117(5), e868-e877.

Mulchan, S. S., Wakefield, E. O., \& Santos, M. (2021). What COVID-19 teaches us about implicit bias in pediatric health care. Journal of Pediatric Psychology, 46(2), 138-143.

Nadal, K. L., Davidoff, K. C., Allicock, N., Serpe, C. R., \& Erazo, T. (2017). Perceptions of police, racial profiling, and psychological outcomes: A mixed methodological study. Journal of Social Issues, 73(4), 808-830.

Nardone, A., Neophytou, A. M., Balmes, J., \& Thakur, N. (2018). Ambient air pollution and asthma-related outcomes in children of color of the USA: A scoping review of literature published between 2013 and 2017. Current Allergy and Asthma Reports, $18(5), 29$.

Okun, T. (2014). Teaching about race and racism: The imperative of history teaching race and anti-racism in contemporary America. Springer.

Pascoe, E. A., \& Smart Richman, L. (2009). Perceived discrimination and health: A meta-analytic review. Psychological Bulletin, 135(4), 531

Post, T. W. (2018). 2015 Washington post database of police shootings. Retrieved from https://www.washingtonpost.com/graphics/ national/police-shootings/

Proctor, J. (2020). Say their names memorial. Retrieved from https:// www.saytheirnamesmemorials.com/press

Reskin, B. (2012). The race discrimination system. Annual Review of Sociology, 38, 17-35.

Schmitt, M. T., Branscombe, N. R., Postmes, T., \& Garcia, A. (2014). The consequences of perceived discrimination for psychological well-being: A meta-analytic review. Psychological Bulletin, 140(4), 921.

Schuck, A. M. (2013). A life-course perspective on adolescents attitudes to police: DARE, delinquency, and residential segregation. Journal of Research in Crime and Delinquency, 50(4), 579-607.

Schwartz, K., Pate, M. R., Tu, W., \& Aalsma, M. C. (2017). Improving police officer knowledge of de-escalation skills: A pilot study of policing the teen brain. Journal of Adolescent Health, $60(2), \mathrm{S} 15-\mathrm{S} 16$.

Scott, K., Ma, D. S., Sadler, M. S., \& Correll, J. (2017). A social scientific approach toward understanding racial disparities in police shooting: Data from the Department of Justice (1980 2000). Journal of Social Issues, 73(4), 701-722.

Sellers, R. M., Caldwell, C. H., Schmeelk-Cone, K. H., \& Zimmerman, M. A. (2003). Racial identity, racial discrimination, perceived stress, and psychological distress among African American young adults. Journal of Health and Social Behavior, 44, 302-317.

Sellers, R. M., Smith, M. A., Shelton, J. N., Rowley, S. A., \& Chavous, T. M. (1998). Multidimensional model of racial identity: A reconceptualization of African American racial identity. Personality and Social Psychology Review, 2(1), 18-39. 
Simons, R. L., Lei, M.-K., Beach, S. R., Barr, A. B., Simons, L. G., Gibbons, F. X., \& Philibert, R. A. (2018). Discrimination, segregation, and chronic inflammation: Testing the weathering explanation for the poor health of Black Americans. Developmental Psychology, 54(10), 1993.

Smith, R. J. (2015). Reducing racially disparate policing outcomes: Is implicit bias training the answer. University of Hawaii Law Review, 37, 295.

Staggers-Hakim, R. (2016). The nation's unprotected children and the ghost of Mike Brown, or the impact of national police killings on the health and social development of African American boys. Journal of Human Behavior in the Social Environment, 26(3-4), 390-399.

Sue, D. W. (2010). Microaggressions in everyday life: Race, gender, and sexual orientation. John Wiley \& Sons.

Thurau, L. H. (2015). First, do no harm: Model practices for law enforcement agencies when arresting parents in the presence of children. Strategies for Youth.

Tyler, T. R., Goff, P. A., \& MacCoun, R. J. (2015). The impact of psychological science on policing in the United States: Procedural justice, legitimacy, and effective law enforcement. Psychological Science in the Public Interest, 16(3), 75-109.
U.S. Census Bureau. (2019). U.S. Census Bureau QuickFacts 2018: United States. Retrieved from https://www.census.gov/quick facts/fact/table/US/PST045217

Valrie, C., Thurston, I., \& Santos, M. (2020). Introduction to the special issue: Addressing health disparities in pediatric psychology. Journal of Pediatric Psychology, 45(8), 833-838.

Vasquez, M. J., Lott, B., García-Vázquez, E., Grant, S. K., Iwamasa, G. Y., Molina, L. E., \& Vestal-Dowdy, E. (2006). Personal reflections: Barriers and strategies in increasing diversity in psychology. American Psychologist, 61(2), 157.

Williams, D. R. (2018). Stress and the mental health of populations of color: Advancing our understanding of race-related stressors. Journal of Health and Social Behavior, 59(4), 466-485.

Publisher's Note Springer Nature remains neutral with regard to jurisdictional claims in published maps and institutional affiliations. 